\title{
Pequeno Manual da Máquina Educacional Moderna: Acompanhado de um Excurso sobre a Situação Atual da Mesma
}

[A Short Manual of the Modern Educational Machine: Followed by a Digression on its Present Situation]

\section{Gabriel Valladão Silva ${ }^{\circledast}$}

Resumo: O texto reúne fragmentos do maquinário filosófico moderno voltado para a crítica do ensino institucionalizado (e em especial da Universidade) como uma espécie de máquina subordinada à grande máquina estatal. Acompanhando o desenvolvimento desse tropo em escritos sobre a sociedade e suas instituições ao longo da modernidade, de Herder a Foucault, procura-se reconstruir a função que ele exerceu na formulação de um discurso crítico sobre um modelo específico de Universidade como instituição pública. A segunda parte do artigo parte do Post-scriptum sobre as sociedades de controle de Deleuze para apontar certos sinais de que, como o próprio Estado, a Universidade passa por uma transformação profunda, que exige uma mudança correspondente na estratégia do discurso crítico associado a ela.

Palavras-chave: Universidade; máquina (tropo); Bildung.

Abstract: This paper gathers pieces of the modern philosophical machinery aimed at the critique of institutionalized education (and especially of the University) as a kind of machine subordinated to the larger machine that is the state. Accompanying the development of this trope in writings on society and its institutions along modernity, from Herder to Foucault, I seek to reconstruct the function that it exercised in the formulation of a critical discourse on a specific model of University as a public institution. The second part of the paper starts with a reading of Deleuze's Post-scriptum on control societies and goes on to point out certain signs that, just as the state itself, the University is going through a deep transformation, which demands a corresponding change in the strategy of the critical discourse associated with it.

Keywords: University; machine (trope); Bildung.

\footnotetext{
${ }^{*}$ Mestre em Filosofia pela Universidade Estadual de Campinas (UNICAMP). Atualmente desenvolve pesquisa de doutorado na Technische Universität Berlin (TU-Berlin), sobre a história do conceito de genealogia na recepção do pensamento de Nietzsche na França dos anos 1960 e 70. E-mail: gvalladao@gmail.com. ORCID: https://orcid.org/0000-0002-7464-4859.
} 
As máquinas não respeitam ninguém; mas você deve respeitá-las.

Carteira de trabalho brasileira, p. 5

1.

Nas primeiras páginas do Leviatã, Hobbes inaugura uma representação da relação entre os indivíduos e a sociedade que acompanhará o mito iluminista do 'contrato social' ao longo da modernidade como uma espécie de contraparte subterrânea. Segundo Hobbes, por meio do contrato social, o ser humano, descrito por ele como uma máquina natural criada por Deus, cria, por sua vez, um "homem artificial", "dotado de proporções e forças maiores que o natural", e que serve à "proteção e defesa" deste: o Estado (HOBBES, 1962, p. ix). 1 Essa impressionante imagem do Estado como uma grande máquina, na qual a pequena máquina humana se insere como peça ou engrenagem, inaugura um tropo recorrente nos séculos seguintes, de que os mais diversos discursos sobre a sociedade moderna, seus fins e ideais, haverão de se servir. Foucault chama-o de "sonho militar da sociedade", que sempre acompanhou e apoiou o "sonho de uma sociedade perfeita" dos filósofos e juristas do século XVIII (FOUCAULT, 1975, p. 198). De acordo com essa visão, também as diversas instituições do Estado moderno - entre elas, e até mesmo com certa proeminência, a Universidade e o 'sistema de ensino' em geral - passam a ser consideradas frequentemente como um conjunto de máquinas subordinadas, cuja função consistiria em produzir, na gigantesca esteira de montagem da sociedade, certos tipos de pessoas, como peças que seriam simultaneamente produtos e partes constitutivas de um grande mecanismo, destinadas a assegurar o seu funcionamento continuado.

\section{2.}

Já Johann Gottfried Herder, um dos primeiros teóricos da Bildung moderna, denuncia a função conservadora e subordinada ao Estado das instituições de ensino das nações modernas, apontando sua função no interior da máquina so-

${ }^{1}$ Todas as citações de textos com referências no original foram traduzidas por mim. 
cial. Para ele, as ciências são flores que necessitam de cultivo e cuidado por parte do governo, mas acima de tudo de espaço e liberdade para germinarem e se desenvolverem de maneira autônoma: "Observai esta planta", escreve Herder, referindo-se à ciência na Grécia antiga,

como cresce ela? Por que ela floresce e prospera? Ela se encontra em seu solo, no lugar que lhe é natural; o ar, o tempo, a estação do ano são favoráveis, e isso basta. $\mathrm{O}$ que ela deve se tornar encontra-se dentro dela e haverá de se produzir por meio de uma força interior. $\mathrm{O}$ solo e o ar fornecem-lhe alimento, o sol the dá calor, o vento, movimento; agora ela se tornará o que deve ser. O arado não torna a terra mais nutritiva, água perfumada não faz a flor desabrochar. $O$ que deve crescer tem de fazê-lo naturalmente, e assim também a flor mais fina do mundo, a ciência, a liberdade da alma (HERDER, 1982 , p. 259 s.).

Segundo Herder, o papel do Es- tado em face da Bildung humana é comparável ao de um jardineiro. Ele deve fornecer as condições favoráveis ao florescimento das ciências, porém jamais poderá forçá-las a ser o que não são, ou a se desenvolver de maneiras que não lhes são naturais. Contudo, o Estado moderno tende a tratar essa planta tão delicada como uma peça a ser moldada segundo o que exige seu mecanismo. É visível, escreve Herder, o "centro" em direção ao qual a Bildung moderna é impelida: "Filosofia! Pensamento! - uma mecânica mais ligeira!" (HERDER, 1994, p. 63)

Para Herder, que a empenhada disseminação do mero 'raciocínio' em todas as camadas da sociedade seja considerada por si só "o ápice e a finalidade de toda Bildung humana, de toda felicidade, de todo bem", longe de ser uma evidência imediata, é um fenômeno especificamente moderno que exige explicação. Segundo ele, seria necessário considerar se com isso o objetivo almejado pelos filósofos da Aufklärung - "formar [bilden] a humanidade" - realmente pode ser alcançado, ou se esse procedimento não terminaria por enfraquecer, em vez de estimular, as inclinações e os impulsos necessários à busca humana por felicidade. Nesse caso, uma tal "exaustão" por meio da instrução exacerbada do máximo de pessoas 
possível teria muito antes efeitos conservadores, e não os efeitos progressivos esperados. "Sem dúvida", escreve Herder,

essa exaustão pode ser cômoda para o espírito de certas nações: membros exaustos têm de seguir adiante, eles não têm forças, a não ser, talvez, para pensar contra [zum Gegendenken]. Cada engrenagem permanece em seu lugar, por medo ou hábito ou opulência e filosofia, e o que são muitos desses rebanhos regidos filosoficamente, senão um bando forçado a se unir gado e lenha! Eles pensam! Dissemina-se o pensamento entre eles - exceto em um ponto: para que se sintam, a cada dia, mais que máquinas, porém segundo preconceitos dados, para que aprendam a ranger e tenham de seguir adiante - eles rangem - ai, não são capazes de outra coisa, a não ser ranger: e refrescam-se com o livre pensar [Freidenken]. O tão querido, débil, desagradável, inútil livre pensar, um substituto para tudo aquilo de que, talvez, precisariam mais: $\mathrm{Co}^{-}$ ração! Calor! Sangue! Humanidade! Vida! (Ibid., p. $63 \mathrm{s.})$

Haveria, pois, segundo Herder, por detrás do "belo ideal" de "ser o que somos" (isto é: "seres humanos"), um "cálculo político" nesse projeto de uma Aufklärung puramente intelectual, cuja máxima secreta seria justamente o inverso do ideal da Bildung que esse projeto supostamente defenderia, a saber: "cada um no uniforme de seu posto, máquinas!” (Ibid., p. 64 s.)

Consequentemente, desse ponto de vista, também os assim chamados "mercados da Bildung da humanidade" - os púlpitos, os tribunais, as bibliotecas, as escolas, as academias etc., estariam a serviço da produção de um mero refresco, do óleo que assegura um funcionamento desimpedido do maquinário estatal. O ser humano que deles participa é estimulado a pensar que, precisamente porque pensa, ele já é mais do que o mecanismo funcional ao qual foi reduzida a sua vida. Nesses locais é jogado um 'jogo' opulento, neles inventam-se princípios universais da liberdade, da honra, da virtude etc., que complementam e tornam suportável o duro trabalho nas engrenagens da sociedade, servindo como uma espécie de válvula de escape, por meio da 
qual a pressão da submissão ao maquinário estatal, transformada no inofensivo vapor do "inútil livre pensar", pode ser liberada sem perigo (ibid.). Essas instituições do livre "pensar contra", tais como Herder as encontra em sua época, serviriam, portanto, acima de tudo, justamente à reprodução da ordem estabelecida e da opressão que pretendem criticar, garantindo, assim, a manutenção da máquina social, em vez de contribuir com sua modificação.

3.

Um forte contraste com essa crítica mordaz ao projeto da Aufklärung é oferecido pelo famoso ensaio de Kant que dá Resposta à pergunta: o que é Aufklärung?, o qual representa como que o negativo do clamor fervoroso de Herder por uma Bildung que fosse mais que um esclarecimento puramente intelectual. Nesse elogio à Aufklärung dedicado ao déspota esclarecido Frederico II - administrador da Prússia, a primeira máquina estatal totalmente moderna -, Kant ressalta justamente o valor positivo da inocuidade do esclarecimento para a ordem so- cial vigente..$^{2}$ Kant assegura ao rei que a pura liberdade de pensamento (nas palavras do filósofo: a liberdade de cada um "de fazer uso público de sua razão"), a única espécie de liberdade que ele pretende defender em seu escrito, é "o mais inofensivo de tudo que possa ser chamado de liberdade". Sim, ele assegura que essa liberdade de pensamento seria até mesmo uma condição necessária da manutenção da ordem social. Porém - eis a famosa tese de Kant -, para que tenha a eficácia esperada, essa liberdade não pode se estender de modo algum ao uso "privado" da razão - isto é, ao uso que se faz dela enquanto funcionário do Estado - sem ameaçar o funcionamento rigorosamente regrado do mecanismo social, do qual depende, também, a liberdade de pensamento puramente intelectual:

Agora, para certas atividades que se dão no interesse da comunidade, é necessário um certo mecanismo, pelo qual alguns membros da comunidade têm de se comportar de maneira meramente pas-

\footnotetext{
${ }^{2}$ Cf. FOUCAULT, 1994, p. 567, que descreve este escrito como uma proposta de uma espécie de contrato „do despotismo racional com a razão livre“, segundo o qual „o uso público e livre da razão autônoma” seria "a melhor garantia da obediência, mas sob a condição de que o princípio político a ser seguido concordasse, ele mesmo, com a razão universal".
} 
siva, para que, por meio de um acordo artificial, sejam direcionados pelo governo para fins públicos, ou, pelo menos, impedidos por ele de destruir tais fins. Ora, certamente, aqui não é permitido raciocinar [räsonnieren]; mas é preciso obedecer. Porém, na medida em que essa peça da máquina se vê ao mesmo tempo como um membro de uma comunidade inteira, sim, até mesmo como cidadão do mundo, portanto na qualidade de um intelectual [Gelehrte] que se endereça a um público em sentido próprio, por meio de escritos, ela pode, decerto, raciocinar, sem que as atividades, nas quais ela, em parte, é inserida como um membro passivo, sejam por isso prejudicadas (KANT, 1977, p. 55 s.).

É nesse sentido que, para Kant, "a era da Aufklärung" é também, em sentido positivo, "o século de Frederico" (ibid., p. 59) (o "minucioso rei das pequenas máquinas, dos regimentos bem adestrados e dos longos exercícios" (FOUCAULT, 1975, p. 161)). Pois para ele apenas uma máquina estatal tão bem regulada por um déspota esclarecido como a Prússia, que "tem à disposição um exército bem-disciplinado e numeroso como garante da tranquilidade pública", pode se permitir dizer ao povo "o que uma república [Freistaat] não pode ousar: raciocinem quanto quiserem, e sobre o que quiserem; apenas obedeçam!" (KANT, 1977, p. 61)

Portanto, assim como para Herder, também para Kant o livre pensar iluminista e a manutenção ou mesmo o aprimoramento da ordem social vão de mão em mão e beneficiam-se mutuamente: um avanço no esclarecimento produz uma sociedade organizada de maneira cada vez mais racional, e esta, por sua vez, possibilita a manutenção de um espaço cada vez maior para o livre pensar. Diferentemente de Herder, porém, Kant considera o avanço dessa reciprocidade um progresso, de modo que chega a lhe parecer desejável aceitar um grau menor de "liberdade civil" em troca de uma maior "liberdade intelectual" [Freiheit des Geistes] (ibid.).

4.

Algumas décadas depois, Wilhelm von Humboldt, ao receber a incumbência de encabeçar uma reforma profunda do sistema de ensino prussiano, buscou, de certo 
modo, conciliar, na prática, as posições contrastantes de Herder e Kant. Sendo conhecido dos antigos membros do Sturm und Drang, Goethe e Herder, assim como dos românticos de sua época, Humboldt, como seu amigo Schiller e tantos outros contemporâneos seus, encontrava-se entre o kantismo e o espinosismo que os primeiros compartilhavam com os Aufklärers berlinenses Lessing e Mendelssohn. 'Espinosista' e, portanto, mais próximo da posição de Herder, era, por exemplo, sua definição do "verdadeiro fim do homem" como "a mais elevada e proporcional Bildung de suas forças como um todo", para cuja tarefa a liberdade e a pluralidade de situações constituiriam as principais condições (HUMBOLDT, 1903, p. 106). $3^{3}$ Acontece que, segundo Humboldt, infelizmente, essas condições se encontram em conflito com a pretensão do Estado de garantir a segurança e o bem-estar dos cidadãos, a qual, consequentemente, não poderia ser promovida em detrimento da Bildung. Para Humboldt, aquele que o fizesse (inclusive o Estado) estaria sob suspeita de "desconhecer a humanidade" e de "querer fazer das pessoas máquinas" (ibid., p. 113 ss.). Consequentemente, no esboço de seu programa para as "instituições científicas superiores" de Berlim, ele estabelece, como um princípio fundamental das mesmas, a exigência de que o Estado se limite a lhes fornecer os meios materiais, no mais imiscuindo-se o mínimo possível em suas atividades (HUMBOLDT, $1903^{2}$, p. 250 ss.). 4 Mas, uma vez que Humboldt - certamente por razões pragmáticas - limita essa exigência às instituições de ensino superior, ele termina por repetir a separação proposta por Kant entre um uso público irrestrito da razão e um uso privado da mesma subordinado aos fins do Estado, a qual, como dito, pelo menos do ponto de vista de Herder, terminaria por impedir a obtenção daquele 'fim verdadeiro' da humanidade, em vez de facilitá-la. Como um funcionário do Estado prussiano encarregado pelo novo rei e por seu ministro von Stein da reforma das instituições de ensino, Humboldt se vê forçado a defender a independência da Universidade com o

\footnotetext{
3 Sobre essa concepção do fim da humanidade cf. por exemplo Mendelssohn acerca da "determinação do homem" (MENDELSSOHN, 1981, p. 115-119), assim como a carta de Mendelssohn a August Hennings do dia 27/11/1784 (Id., ibid., p. 234-237).

4 A proposta posteriormente muito criticada de que o Estado deveria reter o poder de nomear uma parte do corpo docente das Universidades é justificada por Humboldt com o argumento de que isso preservaria a pluralidade de posições no interior das instituições de ensino. Não é este o ponto ao qual quero me ater aqui (cf. ibid., p. 259).
} 
argumento de que, embora o Estado não tenha nenhum interesse imediato naquele 'fim verdadeiro' da humanidade, encontrando-se, muito antes, em conflito com os meios para alcançá-lo, a preservação da liberdade e pluralidade de situações no interior das instituições de ensino e pesquisa haveria, sim, de ser vantajosa para o Estado, uma vez que não apenas o avanço científico lhe seria útil, mas também porque justamente o "caráter" e a "ação" dos cidadãos, que interessam ao Estado, não podem ser impostos de fora, mas têm de ser formados por meio da ciência. Com a fundação da Universidade como local de pesquisa e formação acadêmica, esses dois efeitos se uniam para vantagem do Estado (o que não seria o caso nas Academias da época) (ibid., p. 253).5 Desse modo, o argumento de Humboldt diante da razão estatal de Frederico Guilherme III, assim como o de Kant diante de seu tio-avô, é, no fundo, que a limitação da liberdade ao âmbito puramente intelectual contribuiria com um melhor funcionamento da máquina estatal, com o que, porém, pelo menos do ponto de vista mais radical adotado por Herder, Hum- boldt terminaria por contrariar seu próprio ideal da humanidade.

\section{5.}

Entre os muitos que denunciavam essa subordinação das instituições de ensino ao Estado encontravase também Arthur Schopenhauer, o qual tivera experiências frustrantes como docente na recémfundada Universidade de Berlim, e que, desde então, passou a tratar os professores e pesquisadores universitários com desdém em seus escritos. $\mathrm{O}$ intelectual alienado em sua disciplina seria para ele "análogo ao operário de uma fábrica", "que, durante toda a vida, não faz nada além de produzir um parafuso ou um gancho ou uma alça específica para uma ferramenta ou máquina específica" (SCHOPENHAUER, $1977^{4}$, p. 531). Segundo Schopenhauer, para essa espécie de "sofistas" também a filosofia e a ciência não seriam tarefas vitais, mas somente um "ganha-pão" (SCHOPENHAUER, 1977, p. 16). ! $^{6}$ A Universidade, como instituição estatal, serviria acima de tudo ao objetivo de "produzir nos estudantes a in-

\footnotetext{
${ }^{5}$ Cf. ibid., p. 258: “A Universidade" - em comparação com a academia - "tem uma relação mais próxima com a vida prática e com as necessidades do Estado, uma vez que ela sempre executa por ele as atividades práticas de condução da juventude".

${ }^{6}$ Cf. também o ensaio Ueber die Universitäts-Philosophie (SCHOPENHAUER, 1973, p. 155 ss.).
} 
clinação intelectual [Geistesrichtung] que o ministério responsável por atribuir as cátedras julgar adequada" - o que "do ponto de vista dos governantes" é, também, "corretíssimo", mas que, no entanto, torna a Universidade um "nervis alienis mobile lignum" [sc. uma marionete] que doutrina a juventude de acordo com os fins do Estado, de modo que, em última instância, os professores universitários teriam que ser considerados "adversários" da verdadeira filosofia (SCHOPENHAUER, 1977², p. 190 s.). 7

6.

Foi o jovem professor de filologia Friedrich Nietzsche (o qual, no mais, escreveu muito pouco tanto sobre a Universidade, quanto sobre máquinas) que, nas palestras Sobre o futuro de nossas instituições de ensino proferidas no início de 1872, elevou essas observações a uma crítica realmente mordaz das instituições de ensino alemãs. Embora alguns elementos desse texto - inclusive uma repetição literal da analogia tecida por Schopenhauer entre o intelectual e o operário de fábrica (NIETZSCHE, 1973, p. 162) - apontem para uma influência direta de Schopenhauer sobre o raciocínio de Nietzsche ${ }^{8}$, este vai muito além daquele, potencializando a crítica de Schopenhauer ao, de certo modo, inverter a sua argumentação. Pois, enquanto os insultos de Schopenhauer contra a Universidade se baseiam principalmente na suposta hipocrisia de seus professores, os quais, em sua atividade, não serviriam honestamente a pura verdade, mas estariam secretamente a serviço dos fins do Estado e da Igreja, para Nietzsche, o principal instrumento da doutrinação estatal moderna estaria justamente na liberdade de pensamento e na independência intelectual defendidas por Kant e Schopenhauer e postuladas por Humboldt em seu projeto. Somente essa liberdade tornaria a Universidade uma máquina realmente autônoma, separada da vida dos indivíduos em seu funcionamento automático, que Nietzsche descreve de maneira impactante com as seguintes palavras:

\footnotetext{
7 Também a vantagem da liberdade de imprensa se encontraria, segundo Schopenhauer, no fato de que ela seria capaz de proteger o Estado dos efeitos explosivos do "material mais difícil de manusear", a "raça humana". Ela seria para a "máquina estatal" "o que a válvula de segurança é para a máquina a vapor: pois por meio dela qualquer insatisfação é ventilada imediatamente sob a forma de palavras" (SCHOPENHAUER, 1974, p. 273).

${ }^{8}$ No texto, composto na forma de um diálogo, as teses principais são proferidas por um velho filósofo ermitão que despreza as instituições de ensino. Algumas das posições contidas nessas palestras também aparecem na terceira Consideração extemporânea, Schopenhauer como educador, publicada dois anos mais tarde.
} 
Uma boca que fala e muitos ouvidos, e metade das mãos escrevendo - é esse $\mathrm{o}$ aparato acadêmico externo, é essa a máquina educacional [Bildungsmaschine] da Universidade em funcionamento. No mais, o proprietário dessa boca é separado e independente dos donos dos muitos ouvidos: e essa dupla autonomia é louvada e exaltada como 'liberdade acadêmica'. Além disso, para elevar ainda mais essa liberdade, o primeiro pode dizer mais ou menos o que quiser, e os outros podem ouvir mais ou menos o que quiserem: apenas que, atrás de ambos os grupos, a uma distância modesta, se encontra o Estado com uma certa expressão apreensiva de supervisor, para lembrar de tempos em tempos que ele é o objetivo, o fim e a quintessência desse estranho procedimento de fala e audição (ibid., p. 232).

Para Nietzsche, é justamente a "liberdade acadêmica", isto é, essa aparente separação entre aquilo que se faz, pensa e vive e esse "estranho procedimento de fala e audição" (e escrita) que com- põe a dinâmica do ensino na Universidade, que torna esta última uma peça fundamental do maquinário estatal. Ela é um local de domesticação e disciplinamento da juventude, no qual o comportamento das pessoas (inclusive o próprio 'livre pensar') é tanto mais dominado, quanto mais o processo disciplinador permanece inconsciente, oculto pela ilusão dos sujeitos participantes de que 'na verdade' seriam independentes dele. Assim, a ilusão da liberdade acadêmica, ao relegar o procedimento disciplinar ao âmbito do inconsciente, torna a Universidade uma máquina disciplinadora mais eficiente e automatizada do que qualquer outro aparelho de doutrinação jamais visto.

\section{7.}

Em uma tentativa de ler as palestras Sobre o futuro de nossas instituições de ensino de uma maneira que não levasse necessariamente a uma apoteose do nazismo, Jacques Derrida irá desdobrar a imagem da máquina universitária descrita por Nietzsche no sentido indicado, dizendo aos seus ouvintes (também aqui se trata de uma palestra) o seguinte:

O cão hipócrita [i.e. o Estado] fala aos vossos ouvi- 
dos por meio de seus aparatos escolares, os quais são máquinas acústicas ou acroamáticas. As vossas orelhas crescem, vocês se tornam 'orelhudos', ao, em vez de ouvir e obedecer o melhor mestre e guia com pequenas orelhas, terem a ilusão de ser livres e autônomos de acordo com o Estado, abrindo para ele grandes pavilhões [auriculares], sem saber que ele já se encontra submetido [arraisonné] às forças reativas e degeneradas. Tornados inteiramente orelhas para esse cão-fonógrafo, vocês se transformam em aparelhos receptivos de alta fidelidade, e a orelha, a orelha de vocês, que é também a orelha do Outro, começa, como no caso do 'aleijado invertido', a ocupar um espaço desproporcional em vossos corpos (DERRIDA, 2005, p. 107).

Por meio de um horripilante "cordão umbilical", o Estado não apenas liga os ouvidos dos estudantes imediatamente com suas mãos estenografantes, mas também a boca do professor com $o$ texto que ele decifra, e que sempre já é anterior a ele. Nesse pro- cesso, tudo acontece como que por conta própria, sem nenhuma participação da consciência dos ouvintes e falantes, e esse monstruoso tecido de cordões umbilicais prende todos ao estéril "ventre paterno do Estado", esse "monstro frio, que é um pai morto". Juntos, todos formam um terrível "omphalos", uma figura que é "ao mesmo tempo como uma orelha e como uma boca", uma máquina de peças orgânicas cheia de "dobras invaginadas" e dotada de uma "orificialidade involuta", cujo centro, de onde o Estado dita sua razão estatal como se falasse com a voz da própria vida, se encontra oculto em uma "cavidade invisível, movediça e sensível" (ibid., p. 109 s.).

A imagem que se constitui aqui é a de uma espécie de máquina educacional orgânica, fundida com a própria vida, cujo refinado mecanismo consiste justamente em se confundir com a vida dos seres vivos que nela são integrados para, assim, pô-los a serviço da máquina do Estado sem que eles mesmos o percebam, ou melhor: para que eles mesmos acreditem estar prestando esse serviço 'de livre e espontânea vontade'. Nesse sentido, a máquina educacional moderna descrita por Nietzsche e Derrida não é, como imaginava Schopenhauer, um local de opressão ou de uma mera impo- 
sição externa da doutrina estatal sobre os sujeitos a ela submetidos, mas um tipo de máquina muito mais traiçoeiro, que penetra tão profundamente o tecido orgânico dos indivíduos, modificando suas funções fisiológicas de maneira tão radical e independentemente do conteúdo consciente do que é ensinado e aprendido, que nem parece mais possível separar os indivíduos dela sem pôr suas vidas em risco: eles estão presos ao Estado por meio dessa complexa e invisível rede de cordões umbilicais, e sua energia vital depende dos influxos provindos do "ventre paterno do Estado" . Não há aqui, como ainda havia para Herder e Humboldt, e mesmo para Kant, uma 'humanidade' a ser cultivada por meio da Bildung; pelo contrário, a própria 'humanidade' dessas figuras é um produto da máquina educacional e depende essencialmente da tutela do Estado.

\section{8.}

Vigiar e punir de Michel Foucault fornece provavelmente o relato mais detalhado do desenvolvimento e alastramento dessas máquinas traiçoeiras que, como o "outro lado obscuro" da liberalização política e jurídica da sociedade burguesa, serviram como uma condição subterrânea e oculta de sua existência (FOUCAULT, 1975, p. 258). Para Foucault, os sonhos de uma sociedade perfeita mencionados de início neste artigo, de um lado o sonho filosófico-jurídico e, de outro, o sonho militar, cujos pontos de referência principais não são, como para aquele, o estado de natureza e o contrato social, mas sim "as engrenagens de uma máquina cuidadosamente subordinadas", não são apenas paralelos, nem estão em conflito, mas são, de fato, inseparáveis um do outro (ibid., p. 198).9 Segundo ele, não é por acaso que o mesmo iluminismo que "descobriu" as liberdades, também tenha inventado as disciplinas (ibid., p. 258): pois o próprio indivíduo para o qual devem valer essas liberdades, longe de possuir uma natureza livre originária, não é ele mesmo nada mais que um produto dessas 'tecnologias' do poder:

\footnotetext{
${ }^{9}$ Cf. ibid., p. 215 s.
} 
forças e dos corpos. Nós [...] estamos [...] dentro da máquina panóptica, investidos por seus efeitos de poder que nós mesmos reconduzimos, pois nós somos uma engrenagem sua (ibid., p. 253).

Uma mensagem fundamental de Vigiar e punir é que, na sociedade da disciplina, o próprio corpo se constitui desde o início "como peça de uma máquina multisegmentária” (ibid., p. 193); os indivíduos que a ela pertencem não têm nenhuma outra natureza além daquela para a qual foram 'fabricados', nenhuma 'humanidade' essencial oprimida e desfigurada pelos mecanismos de poder. Para Foucault, não são tanto os engodos da ideologia que levam os membros da sociedade burguesa a abrir mão de uma liberdade e autodeterminação originárias. As forças do homem não têm uma direção natural à qual o cultivo da Bildung deve se adaptar; pelo contrário, o indivíduo, sua consciência, até mesmo sua 'liberdade', são constituídos por meio de práticas em grande medida independentes de conteúdos representacionais. 10 Assim como para Nietzsche/Derrida, a vida encontra-se aqui entrelaçada até o âmago com 'tecnologias do poder', de modo que mal é possível afirmar que ainda haja uma vida a ser libertada dessas tecnologias. $\mathrm{O}$ paradigma da máquina, da fabricação, substitui o paradigma orgânico que orientava as críticas à sociedade moderna, de Herder a Marx. A ciência, a Bildung moderna, não é, como o queria Herder, uma flor desfigurada pelo maquinário estatal; ela não possui um potencial intrínseco que é meramente bloqueado ou desviado pela ordem burguesa vigente; ela é, desde o início, um produto de fábrica, uma produção da sociedade moderna que supostamente a reprime. Dessa maneira, deste ponto de vista, também a Universidade moderna, com toda a liberdade acadêmica e independência de opinião que lhe pertencem, deve aparecer como uma instituição da disciplina entre tantas outras, a qual, independentemente dos conteúdos nela ensinados e aprendidos, já por meio de sua mera arquitetônica, de seu mero funcionamento, adestra os corpos (as orelhas, os olhos, as mãos, o

\footnotetext{
${ }^{10}$ Cf. ibid., p. 227: “Sem dúvida, o indivíduo é o átomo ficcional de uma representação 'ideológica' da sociedade; mas ele é também uma realidade fabricada por essa tecnologia específica de poder chamada 'disciplina'. É preciso deixar de sempre descrever os efeitos de poder em termos negativos [...]. De fato, o poder produz; ele produz coisas reais [du réel]; ele produz domínios de objetos e rituais de verdade. O indivíduo e o conhecimento que dele podemos obter dependem dessa produção".
} 
proverbial ' $c *$ de ferro'...) e produz certos tipos de indivíduos úteis à máquina social.

$$
* * *
$$

Naturalmente, a longa, porém fragmentária sequência aqui exposta não exaure todo o espectro em que o tropo maquinal se estende no pensamento sobre a sociedade, o Estado e suas instituições de ensino desde o século XVIII. Sem dúvida, seria igualmente possível traçar caminhos totalmente distintos para contar a mesma história, como por exemplo o do desenvolvimento da representação do homem como máquina, que vai mais ou menos de Descartes até a psicologia empírica do século XX (para não mencionar o conceito das machines désirantes de Deleuze e Guattari), passando pelo 'homem-máquina' de La Mettrie; ou também a história da representação do universo como um grande e maravilhoso artefato mecânico, do demônio de Laplace e os mecanicistas 'clássicos' até os nano-mecanismos antiintuitivos da mecânica quântica, os quais podem ser (e foram) lidos, em seu conjunto, como sintomas de um modo de pensar no interior de um certo tipo de sociedade.11 Também Marx dedica o capítulo 13 do primeiro volume do Capital a uma apresentação da fusão (de modo algum metafórica) entre o maquinário industrial e a sociedade, por meio da qual o trabalhador é reduzido a uma "parte de uma máquina parcial" [Theil einer Theilmaschine] no interior do complexo industrial (MARX, 1991, p. 380) - uma relação que, ademais, Adorno e Horkheimer, pela metade do século XX, se esforçaram por demonstrar também na assim chamada indústria cultural. De modo geral, como em $\mathrm{Vi}$ giar e punir, também na Dialética do esclarecimento a figura da máquina é utilizada constantemente para ilustrar criticamente a sociedade, o indivíduo e até mesmo a degradação do pensamento em um "maquinário pensante" (ADORNO, HORKHEIMER, 1969, p. 31 ss.).

Portanto, não se trata aqui de traçar um itinerário completo, nem mesmo de determinar o sentido de toda essa 'maquinação' teórica aqui reunida. Tentei apenas enumerar e organizar, nos fragmentos aqui escolhidos e analisados, como que peças de uma máquina que poderia muito bem 'funcionar' (todo livro é uma

\footnotetext{
${ }^{11} \mathrm{O}$ próprio Foucault menciona o grande livro de duas faces do "homem-máquina", o qual, durante a modernidade, foi escrito tanto do lado "anatomo-metafísico", como do lado "técnico-político" (ibid., p. 160 s.).
} 
"pequena máquina", dizem Deleuze e Guattari, na qual não se trata de saber o que ela significa, mas apenas "com o que funciona" (DELEUZE, GUATTARI, 1980, p. 10)); peças de uma máquina teórica, portanto, que se encontra em uma relação múltipla e complexa com a própria máquina universitária, uma vez que, de um lado, ela lhe é externa e hostil como uma espécie de 'máquina de guerra', mas, de outro, devido à forma 'erudita', à escolha do material etc., permanece atada a ela, alimentando-se dela e dependendo dela.

Vista através dessa máquina montada a partir de peças modernas, a Universidade aparece como uma espécie muito peculiar de astúcia, como um mecanismo elaborado, dotado de efeitos altamente refinados, quase imperceptíveis, e, não obstante, muito profundos, como uma ferramenta de grande eficácia e precisão, desenvolvida para a reprodução e o aperfeiçoamento da grande máquina social moderna da qual ela mesma é uma peça. - Porém, do ponto de vista atual, cabe perguntar se, e em que medida, uma tal máquina teórica ainda pode ser conectada com as instituições de ensino superior de nossos dias; se o último grande complexo industrial de máquinas produzido pela modernidade, a Segunda Guerra Mundial, em cujo centro se encontrava a máquina mortífera Auschwitz, não seria um sinal de declínio do tipo de 'máquina' ao qual também pertence a Universidade moderna; e, consequentemente, se, com essa mudança, o topos maquinal tão fértil na teoria moderna também não haverá de perder pelo menos uma parte de sua potência crítica, precisando ser reformulado. Hitler e Stalin talvez tenham sido os últimos operadores de um aparato estatal totalitário tipicamente moderno que nascera com Napoleão e Frederico II.12 O assim chamado Estado neoliberal que, a partir dos anos 1970, após o New Deal e o sucesso temporário do Welfare State, aos poucos ganhou preponderância nas democracias ricas, e que já há algum tempo vem se exportando para o mundo todo, parece, em todo caso, ser algo distinto de uma grande máquina a vapor. E, com isso, as instituições cuja principal tarefa até então fora produzir as engrenagens dessa máquina - as escolas, os hospitais, as ca-

\footnotetext{
${ }^{12}$ Herbert Marcuse descreveu de maneira especialmente impactante o Estado nacional-socialista como uma máquina gigantesca, inapreensível para o indivíduo (MARCUSE, 2000). O próprio Stalin proferiu a famosa frase: "O Estado é uma máquina nas mãos da classe dominante para a supressão da resistência de seus inimigos de classe. Deste ponto de vista a ditadura do proletariado não se diferencia essencialmente da ditadura de qualquer outra classe, pois o Estado proletário é uma máquina para a supressão da burguesia” (STALIN, 1946, p. 30).
} 
sernas, as prisões etc., e, é claro, as Universidades - estariam também em um processo de profunda transformação.

Um importante impulso para a reflexão sobre essas mudanças foi dado por Gilles Deleuze em um de seus últimos escritos, o desde então muito discutido Postscriptum sobre as sociedades de controle (1990). Aqui, ele parte precisamente dessa observação de que, atualmente, somos testemunhas de uma crise geral de todas as instituições que caracterizavam a sociedade da disciplina descrita por Foucault - uma crise que, aliás, segundo ele, também pode ser ilustrada por meio de uma analogia com tipos de máquinas. De acordo com Deleuze, é possível pensar um tipo de máquina que corresponda a cada tipo de sociedade, "não porque as máquinas são determinantes, mas porque elas expressam as formas sociais capazes de dar luz a elas e de se servir delas". Desse modo, recentemente, às "máquinas simples" das "sociedades de soberania" ("alavanca, roldana, relógios") e às "máquinas energéticas" das "sociedades da disciplina" (como máquinas a vapor e motores) se uniram certas "máquinas de terceira espécie", "máquinas informáticas e computadores", cujo aparecimento poderia apontar para uma mudança correspon- dente na forma da sociedade (DELEUZE, 2003, p. 244).

Segundo a sugestão de Deleuze, essa mudança deve ser compreendida como uma passagem das sociedades da disciplina descritas por Foucault para um tipo de sociedade que ele chama de sociedade de controle, a qual se distingue da anterior principalmente pelo fato de não precisar mais de espaços rigorosamente estruturados para 'formar' as pessoas à sua imagem. Enquanto, segundo Deleuze, os espaços das sociedades da disciplina (a prisão, a escola, a fábrica etc.) podem ser entendidos como diferentes "moldes", os "controles" são mais como uma espécie de "modulação", isto é, "algo como um molde que se auto-transfigura, que se modifica constantemente" (ibid., p. 242). Desse modo, a indústria, por exemplo, encarnada na concretude da fábrica e do parque industrial, dá lugar à empresa (e, no limite, à "empresa de si mesmo"), muito mais etérea e volátil que aquela; o próprio capitalismo passa da produção à superprodução, da sociedade industrial à sociedade dos serviços, do padrão-ouro ao câmbio flutuante etc. Correspondentemente, também as pessoas não são mais distribuídas em espaços descontínuos e fechados, nos quais lhes são imprimidas figuras determi- 
nadas, quer dizer, elas não vão mais necessariamente da família à escola, de lá para a caserna, e então para a fábrica ou para a universidade etc., mas participam cada vez mais de uma nova forma de Bildung, que consiste na modificação e reconfiguração constante da individualidade por meio de 'modulações': daí a crise das instituições da disciplina diagnosticada por Deleuze.

É importante notar que não se trata de questionar se essa nova forma social que se configura é mais 'branda', 'humana' ou, de modo geral, melhor ou pior que as anteriores: a maneira pela qual o poder age apenas se modifica, aos nossos olhos ele se torna mais fugaz, menos visível, mais 'espiritualizado': assim como os vultosos 'cérebros eletrônicos' dão lugar aos computadores, estes aos laptops e notebooks, e estes, por sua vez, aos smartphones, o Estado vai se tornando 'mínimo' aos nossos olhos - mas já Foucault nota com vistas à sociedade da disciplina que essa relativa invisibilidade do poder não significa de modo algum que ele esteja desaparecendo. A máquina só é mais difícil de reconhecer quando se é uma peça em seu interior. No modelo proposto por Deleuze trata-se, muito antes, de chamar a atenção para certas mudanças estruturais na sociedade e incitar a reflexão so- bre elas, pois com a transformação da máquina social se transformam também as formas de resistência eficazes contra ela (DELEUZE, $2003^{2}$, p. 237). Deveríamos nos perguntar, por exemplo, se nessa nova 'máquina' social ainda faz sentido falar das pessoas como 'engrenagens' em um mecanismo - talvez o trabalhador de hoje esteja mais próximo de um dispositivo de memória RAM, que deve poder, segundo a necessidade, ser preenchido com estes ou aqueles dados ou também esvaziado novamente, ou de um ponto nodal móvel no interior de uma rede fluida de informações. A nova imagem da sociedade requer uma renovação do vocabulário em que a crítica contra ela é formulada. As máquinas relevantes para ela não são mais espalhafatosas máquinas a vapor, nem motores elétricos ou de combustão, mas os pequenos e poderosos aparelhos que cada cidadão carrega diariamente rente ao corpo.

Desse ponto de vista, também no caso da educação seria igualmente superficial dizer que ela diminui com o atrofiamento das instituições estatais destinadas a produzi-la; ela parece muito antes se deslocar progressivamente do Estado para o mercado. Ela não diminui, mas, pelo contrário, se torna mais longa, contínua, 'flexível' - ela se transforma 
de uma instância da disciplina ("molde") em uma instância do controle ("modulação"). À medida que o próprio Estado, em sua forma neoliberal, se torna uma máquina cada vez mais minúscula a serviço da manutenção dos mecanismos do mercado, também as instituições que serviam o Estado passam a se subordinar progressivamente às forças do mercado; seja diretamente, desligando-se por completo do Estado, ou indiretamente, através do Estado agora subordinado ao mercado.

O papel do crítico da Bildung é refletir sobre quais novas formas de resistência e de crítica ainda são possíveis nessa nova situação. Quando o discurso crítico da modernidade que denunciava o elo das instituições de ensino com uma forma específica de poder passa ao serviço de uma nova forma de poder, é fundamental repensar as estratégias desse discurso. Que não sejam mais Schopenhauer ou Nietzsche, mas o próprio presidente Bolsonaro e o seu ministro da educação Abraham Weintraub a denunciar o 'aparelhamento' da Universidade pelo Estado, é um sinal jus- tamente de que a Universidade já teria talvez deixado de ocupar a função de aparelho a serviço do Estado pela qual tanto fora criticada ao longo da modernidade. Com isso, essa crítica perde não só em força, mas em legitimidade. Quando o próprio Estado, em sua forma neoliberal, passa ao serviço do desmonte da máquina educacional que servia o estado-nação moderno, substituindo-a por formas modulares e flexíveis de 'educação continuada' integradas às demandas do mercado, é porque, nessa nova conjuntura, essa máquina deixou de ser uma engrenagem no interior da máquina estatal, para se tornar um empecilho, uma roda que já não se encaixa mais no pequeno e enxuto aparelho de controle que se tornou o Estado, atravancando e atrapalhando os mecanismos das novas formas de poder em ascendência. ${ }^{13}$ Ao perder sua utilidade para o poder instituído, a Universidade pública se torna uma instituição anacrônica, que não se encaixa na imagem que esse poder tem do futuro da educação, conforme demonstram os 'estímulos' à 'autonomização financeira' de

\footnotetext{
13 Ademais, é preciso ter em mente que o funcionamento de nenhum aparelho pode ser reduzido integralmente à sua função. Todo mecanismo produz uma quantidade de entropia, um resto que não pode ser transformado em trabalho útil. Nesse sentido, toda instituição, mesmo no auge de sua conformidade com o mecanismo de que faz parte (e tanto mais em um momento de crise e desagregação), contém um elemento de resistência inextinguível. O exemplo do hegelianismo de esquerda demonstra que mesmo a filosofia eminentemente 'universitária', em certos aspectos até mesmo 'estatal' de Hegel, engendra um 'resto' que transborda o quadro em que foi concebida.
} 
programas como o Future-se proposto pelo Ministério da Educação em meio a uma crise orçamentária e uma guerra ideológica em torno das instituições públicas de ensino no Brasil. O papel da crítica é tornar justamente esse anacronismo uma força extemporânea, no sentido nietzschiano da palavra, como uma força que, ao agir "contra o tempo", age também "sobre o tempo" e "em prol de um tempo vindouro" que já não seja mais a mera 'futurização' do presente, mas um tempo verdadeiramente outro (NIETZSCHE, 1972, p. 243). Correspondentemente, a luta pela preservação dessa máquina, que em outros tempos poderia ser considerada uma luta conservadora, torna-se, na situação atual, uma forma de resistência: e é isso, de certo modo, o que se vê hoje no Brasil, onde a defesa do ensino público, gratuito e de qualidade foi uma das mais fortes bandeiras capaz de mobilizar uma parcela significativa da população até agora. Tudo isso indica que, uma vez rompido o seu laço com o Estado, a máquina universitária, alienada da função disciplinadora que exerceu durante a modernidade, adquire o potencial de se transformar em uma verdadeira 'máquina de guerra' na luta por uma visão do futuro alternativa àquela apresentada pelo paradigma neoliberal.

\section{Referências}

ADORNO, T. W., HORKHEIMER, M. Dialektik der Aufklärung. Philosophische Fragmente. Frankfurt a.M.: S. Fischer, 1969.

DELEUZE, G. Contrôle et devenir. In: Pourparlers. Paris: Éditions de Minuit, 2003.

DELEUZE, G., Post-scriptum sur les sociétés de contrôle. In: Pourparlers. Paris: Éditions de Minuit, 20032.

DELEUZE, G., GUATTARI, F. Capitalisme et schizophrénie 2. Mille plateaux. Paris: Éditions de Minuit, 1980.

DERRIDA, J. Otobiographies. L'enseignement de Nietzsche et la politique du nom propre. Paris: Éditions Galilée, 2005.

FOUCAULT, M. Surveiller et punir. Naissance de la prison. Paris : Gallimard, 1975.

FOUCAULT, M. Qu'est-ce que les lumières?. In: Dits et écrits, IV, Paris: Gallimard, 1994.

HERDER, J. G. Vom Einfluss der Regierung auf die Wissenschaften und der Wissenschaften auf die Regierung. In: Herders Werke in fünf Bänden, 3, Berlim/Weimar: Aufbau, 1982.

HERDER, J. G. Auch eine Philosophie der Geschichte zur Bildung der Menschheit. In: Werke in zehn Bänden, 4, Frankfurt a.M.: Deutscher Klassiker Verlag, 1994.

HOBBES, T. Leviathan. In: The English Works of Thomas Hobbes of Malmesbury, III. Aalen: Scientia, 1962.

HUMBOLDT, W. Ideen zu einem Versuch die Grenzen der Wirksamkeit des Staats zu bestimmen. In: Gesammelte Schriften, I. Berlim: B. Behr, 1903.

HUMBOLDT, W. Über die innere und äußere Organisation der höheren wissenschaftlichen Anstalten in Berlin. In: Gesammelte Schriften, X. Berlim: B. Behr, 19032. 
KANT, I. Beantwortung der Frage: Was ist Aufklärung?. In: Idem. Werkausgabe, XI. Frankfurt a.M.: Suhrkamp, 1977.

MARCUSE, H. Staat und Individuum im Nationalsozialismus. taz.de, 2000.

Disponível em [http://www/taz.de/!1207627/]: acessado em [19/12/2018]. Traduzido do inglês por Michael Haupt.

MARX, K. Das Kapital. Kritik der politischen Ökonomie, 1. In: Karl Marx Friedrich Engels Gesamtausgabe, II,10. Berlim: Akademie Verlag, 1991.

MENDELSSOHN, M. Über die Frage: Was heißt Aufklärung?. In: Gesammelte Schriften, 6,1. Stuttgart/Bad Cannstatt: frommann-holzboog, 1981.

MENDELSSOHN, M. Briefwechsel III. In: Gesammelte Schriften, 13. Stuttgart/Bad Cannstatt: frommannholzboog, 19812.

NIETZSCHE, F. Vom Nutzen und Nachteil der Historie für das Leben. In: Werke. Kritische Gesamtausgabe, III,1. Berlim/Nova Iorque: De Gruyter, 1972.

NIETZSCHE, F. Über die Zukunft unserer Bildungsanstalten. In: Werke. Kritische Gesamtausgabe, III,2. Berlim/Nova Iorque: De Gruyter, 1973.

SCHOPENHAUER, A. Die Welt als Wille und Vorstellung, I. In: Züricher Ausgabe. Werke in zehn Bänden, I/II. Zurique: Diogenes, 1977.

SCHOPENHAUER, A. Die Welt als Wille und Vorstellung, II. In: Züricher Ausgabe. Werke in zehn Bänden, II/III. Zurique: Diogenes, 19772.

SCHOPENHAUER, A. Ueber die Universitäts-Philosophie. In: Züricher Ausgabe. Werke in zehn Bänden, VII. Zurique: Diogenes, 19773.

SCHOPENHAUER, A. Parerga und Paralipomena II. In: Züricher Ausgabe. Werke in zehn Bänden, IX/X. Zurique: Diogenes, 19774.

STALIN, J. Über die Grundlagen des Leninismus. Vorlesungen gehalten an der Swerelow-Universität Anfang April 1924. In: Über die Grundlagen des Leninismus; Zu den Fragen des Leninismus. Berlim: Neuer Weg, 1946.

Recebido: $08 / 10 / 2019$

Aprovado: $16 / 11 / 2019$

Publicado: $26 / 01 / 2020$ 